\section{Single-step endoscopic ultrasound-guided fluoroless gallbladder drainage using the Axios lumen-apposing metal stent}

Severe acute cholecystitis is a condition that requires urgent surgical intervention to prevent sepsis and death. Elderly patients can be unfit for surgery because of comorbidities so alternative techniques are required for gallbladder drainage [1]. Here we report the case of a 93-year-old woman with abdominal pain, fever, and vomiting who was referred to our unit to undergo gallbladder drainage. An abdominal computed tomography (CT) scan showed cholelithiasis, gallbladder distension with wall thickening, and peri-cholecystic fluid. However, because of renal and cardiorespiratory comorbidities, the patient was judged unfit for surgery.

Fluoroless endoscopic ultrasound (EUS)guided transluminal gallbladder drainage was therefore performed using a fully covered metal stent $(10 \mathrm{~mm}$ in diameter; Hot Axios, Boston Scientific Inc., Natick, Massachusetts, USA). The gallbladder was directly punctured using the cautery tip of the device. This was possible owing to a favorable position of the gallbladder, which was closely abutting the duodenum. The lumen-apposing metal stent (LAMS) was then deployed, with subsequent rapid drainage of the gallbladder. The patient became asymptomatic in the days following the procedure and was discharged 5 days later.

EUS-guided transmural gallbladder drainage, which has been practiced since 2007 , requires multiple steps and devices to achieve gallbladder access, dilation of the duodenal wall, and stent deployment [1]. The need for device exchange over a wire can result in an increased risk of adverse events, such as perforation, bleeding, and infection. Furthermore, until now, the stents used for these indications have had

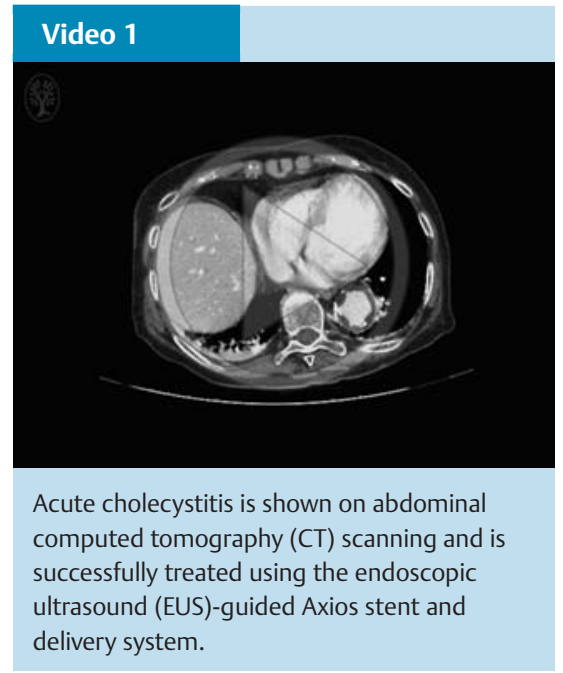

to be borrowed from those intended for use during endoscopic retrograde cholangiopancreatography (ERCP).

The Axios system is a new specifically designed fluoroless EUS-guided fully covered lumen-apposing metal stent, which is used for drainage of pancreatic fluid collections, the gallbladder, and the bile duct $[2,4,5]$. The Axios delivery system provides good maneuverability and visibility, making the sheath suitable for direct puncture.

Our experience suggests that EUS-guided gallbladder drainage should be considered as a first option in patients unfit for surgery [3]. This new device may be easier to deploy than other stents and maintains good apposition of the two walls to create an iatrogenic anastomosis.

\section{Endoscopy_UCTN_Code_TTT_1AS_2AD}

Competing interests: None

\section{Carmelo Barbera, Giuseppe Grande, Nadia Alberghina, Mauro Manno, Rita Luisa Conigliaro}

Gastrointestinal Endoscopy Unit, NOCSAE Hospital, Modena, Italy

\section{References}

1 Kwan V, Eisendrath P, Antaki $F$ et al. EUSguided cholecystenterostomy: a new technique. Gastrointest Endosc 2007; 66: $582-$ 586

2 Walter $D$, Teoh AY, Itoi $T$ et al. EUS-guided gallbladder drainage with lumen-apposing metal stent: a prospective long-term evaluation. Gut 2016; 65: 6-8

3 Anderloni A, Buda A, Vieceli $F$ et al. Endoscopic ultrasound-guided transmural stenting for gallbladder drainage in high-risk patients with acute cholecystitis: a systematic review and pooled analysis. Surg Endosc. Epub ahead of print 2016 Apr 8

4 Galasso D, Baron TH, Attili F et al. Endoscopic ultrasound-guided drainage and necrosectomy of walled-off pancreatic necrosis using a metal stent with an electrocautery-enhanced delivery system. Endoscopy 2015; 47 (Suppl. 01): E68

5 Kunda R, Pérez-Miranda M, Will U et al. EUSguided choledochoduodenostomy for malignant distal biliary obstruction using a lumen-apposing fully covered metal stent after failed ERCP. Surg Endosc. Epub ahead of print 2016 Mar 11

\section{Bibliography}

DoI http://dx.doi.org/

10.1055/s-0042-111391

Endoscopy 2016; 48: E254

(c) Georg Thieme Verlag KG

Stuttgart · New York

ISSN 0013-726X

\section{Corresponding author} Giuseppe Grande, MD

Gastrointestinal Endoscopy Unit

NOCSAE Hospital

via Pietro Giardini 1355

Baggiovara di Modena

Modena 41126

Italy

Fax: +39-059-3961216

giuseppegrande1984@gmail.com 